\title{
Histopathology of Kabatana arthuri (Microspora) infection in sutchi catfish, Pangasius sutchi
}

\author{
Iva Dyková and Jiří Lom
}

Institute of Parasitology, Academy of Sciences of the Czech Republic, České Budějovice, Branišovská 31, 37005 České Budějovice, Czech Republic

Key words: histopathology, Kabatana arthuri, microsporidia, spore dispersal, Pangasius

\begin{abstract}
The microsporidian Kabatana arthuri (Lom, Dyková et Shaharom, 1990) induced severe regressive changes in trunk muscles of Pangasius sutchi (Fowler) from Thailand. Necrotic changes developed in muscle fibres around the developmental stages and on the periphery of giant aggregates of spores. The main feature of the host defence reaction was the phagocytic activity of macrophages. Inflammatory reaction was only exceptionally observed. Spore-laden macrophages were found in various tissues and organs; their infiltration in epidermis including its outermost layers may effectively enhance the spread of infection while the hosts still live.
\end{abstract}

Skeletal muscles of bony fishes serve as the specific site of development of many microsporidian species of the genera Heterosporis Schubert, 1969 and Pleistophora Gurley, 1893 and of the collective group Microsporidium. Species of some other microsporidian genera, like Glugea Thelohan, 1891 or Tetramicra Matthews et Matthews, 1980 do not infect sarcocytes, but connective tissue cells in trunk musculature. The general pattern of the course of microsporidian muscle tissue infection in fish has been outlined in several publications (e.g., Dyková and Lom 1980, Canning and Lom 1986, Shaw and Kent 1999) - muscle fibres are replete with parasite stages and later with spores and do not undergo a xenoma-like hypertrophy; the parasite foci are later encapsulated or destroyed by macrophages and eventually, a granuloma forms. Studies on the interaction between various fish hosts and their microsporidian parasites, resulting in histopathological changes, may bring additional knowledge on fish tissue reaction and on the outcome of specific cases of host parasite interaction. Considering that microsporidia infecting skeletal muscles are mostly serious pathogens of fish, we suppose that our observation presented below may usefully complete the existing data.

Pangasius sutchi (Fowler, 1937) is an important species of commercial food fish and young fish are used as ornamental fish. In a fish farm in Bangkok region (Thailand) specimens displaying anomalous behaviour and whitish areas showing through the skin were found. Microscopical examination confirmed the presence of a microsporidian which was originally identified as Microsporidium arthuri Lom, Dyková et Shaharom, 1990 and recorded from the same host (Lom et al. 1990). On the basis of an ultrastructural study a new genus, Kabataia, was subsequently created (Lom et al.
1999). Since the name was already in use for a parasitic copepod, a new genus, Kabatana Lom, Dyková et Tonguthai, 2000 has been proposed (Lom et al. 2000).

\section{MATERIALS AND METHODS}

Four infected specimens of Pangasius sutchi collected in a fish farm in the Bangkok region (Thailand) were examined; in two, the infection was apparent as white patches visible through the skin. To describe the location and extent of lesions, the entire fish bodies of all specimens (length $3.5 \mathrm{~cm}$ ) were fixed in Davidson's fixative modified for freshwater fish tissues. Samples were embedded in Histoplast-S (Serva) and sectioned parallel to the long axis of the fish body. Histological sections were routinely stained with haematoxylin and eosin (H\&E), Trichrome and Giemsa stains.

\section{RESULTS}

The main histological changes induced by Kabatana arthuri (Lom, Dyková et Shaharom, 1990) in P. sutchi were found in the lateral musculature, i.e., in dorsal muscle (m. laterodorsalis) and ventral muscle (m. lateroventralis). Most of the blocks of lateral musculature were replaced with aggregated spores and presporogonic developmental stages (Figs. 1, 2). The damage caused by the agent was more extensive than indicated by gross lesions (emaciation). Two types of infection were observed. Severe regressive changes in muscle tissue which accompanied multiplication of microsporidia and the spread of infection predominated in three specimens. In addition to dystrophic changes of muscle fibres characterised by disappearance of striations (Fig. 5 compare with Fig. 4), myonecrosis was observed around developmental stages as well as on the periphery of giant aggregates of spores (Figs. 3, 5). These aggre-gates grew in size more or less radially (Fig. 5). 


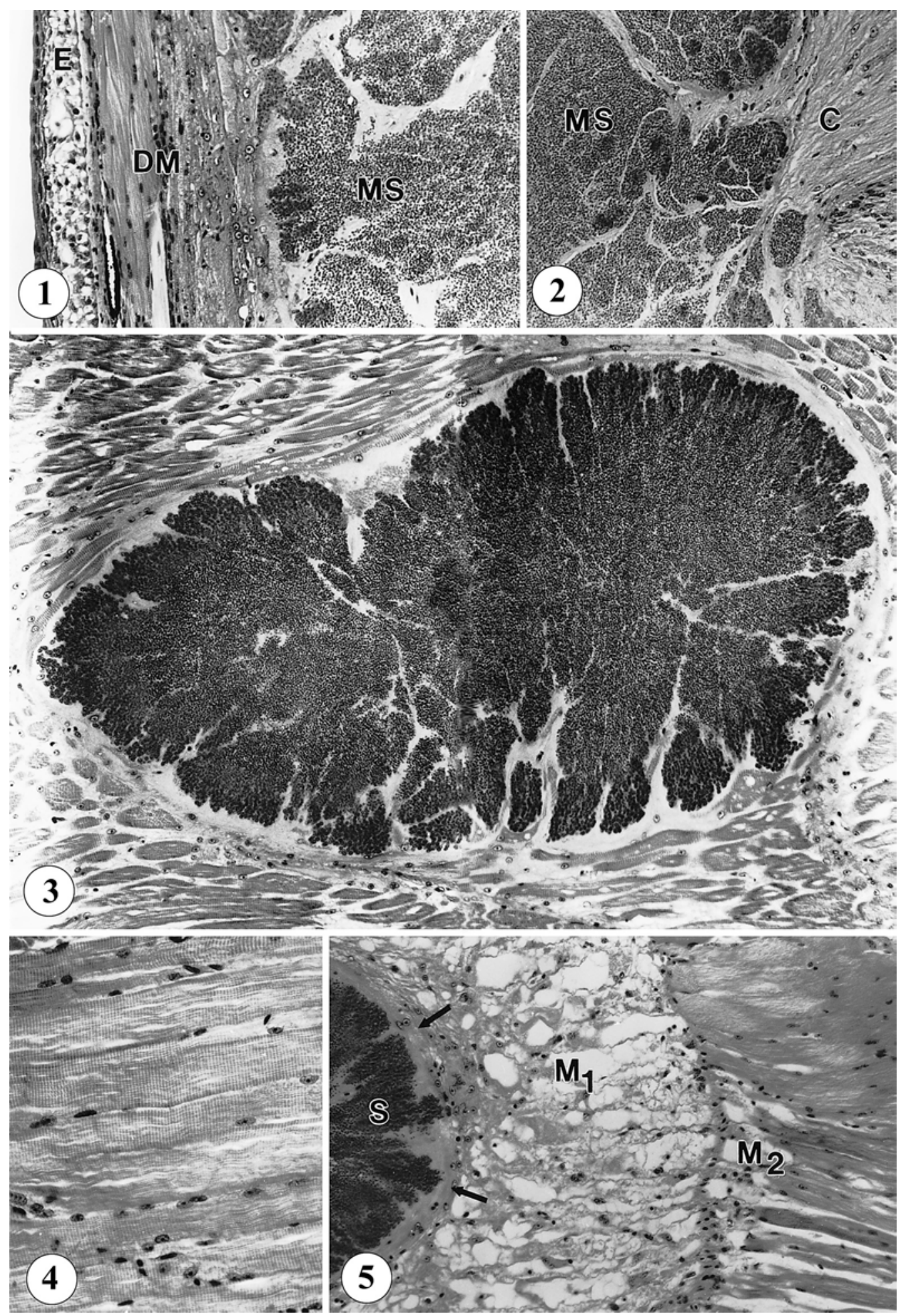

Figs. 1-5. Tissues of Pangasius sutchi infected with Kabatana arthuri, H\&E. Fig. 1. Transverse section through the body wall (the skin is to the left) of $P$. sutchi showing a large mass of mature spores. E - epidermis; DM - dorsal muscle (musculus laterodorsalis); MS - spores. $\times$ 195. Fig. 2. Lateral muscle replaced with spores (MS) throughout the cross-section up to the vertebrae. C - connective tissue enveloping the vertebral body. $\times 195$. Fig. 3. Longitudinal section of the ventral muscle (musculus lateroventralis) showing a large focus of infection. $\times 190$. Fig. 4. Longitudinal section of an intact skeletal muscle $(\times 320)$ to compare with Fig. 5. showing regressive changes of two myosepta $\left(M_{1}, M_{2}\right)$ adjacent to a giant aggregate of mature spores (S) encased with a thin connective tissue envelope (arrow). $\times 310$. 


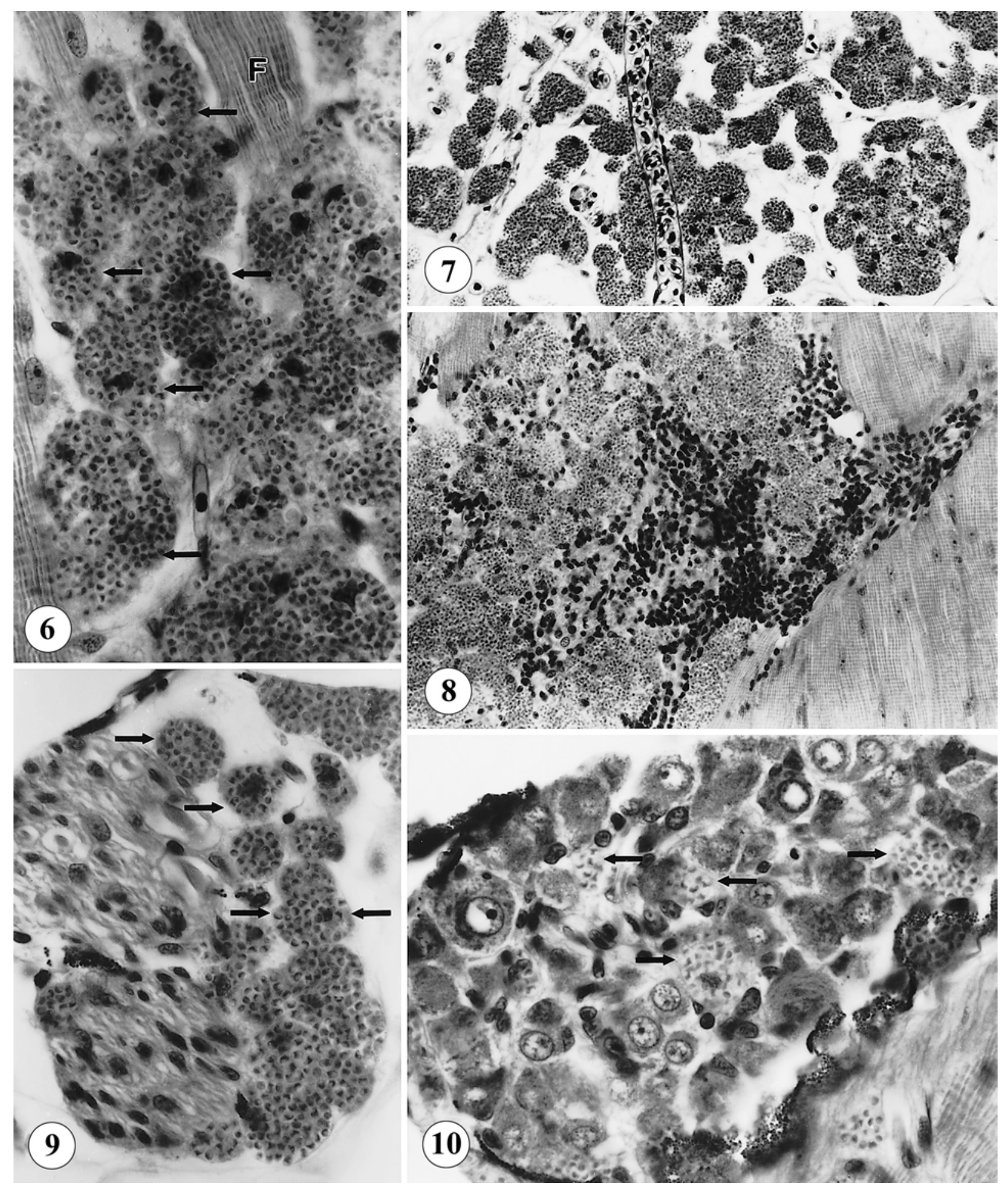

Figs. 6-10. Tissues of Pangasius sutchi infected with Kabatana arthuri, H\&E. Fig. 6. Macrophages (arrows) replete with spores among still preserved muscle fibres (F). $\times 880$. Fig. 7. Macrophages packed full with spores, accumulated along a blood vessel in connective tissue. $\times 280$. Fig. 8. Myositis with lymphocytes infiltrated among macrophages packed with spores. $\times 420$. Fig. 9 . Spore-replete macrophages (arrows) close to a peripheral nerve. $\times 860$. Fig. 10. Spore-containing macrophages (arrows) among nerve cells in the ganglion of a spinal nerve. $\times 910$. 

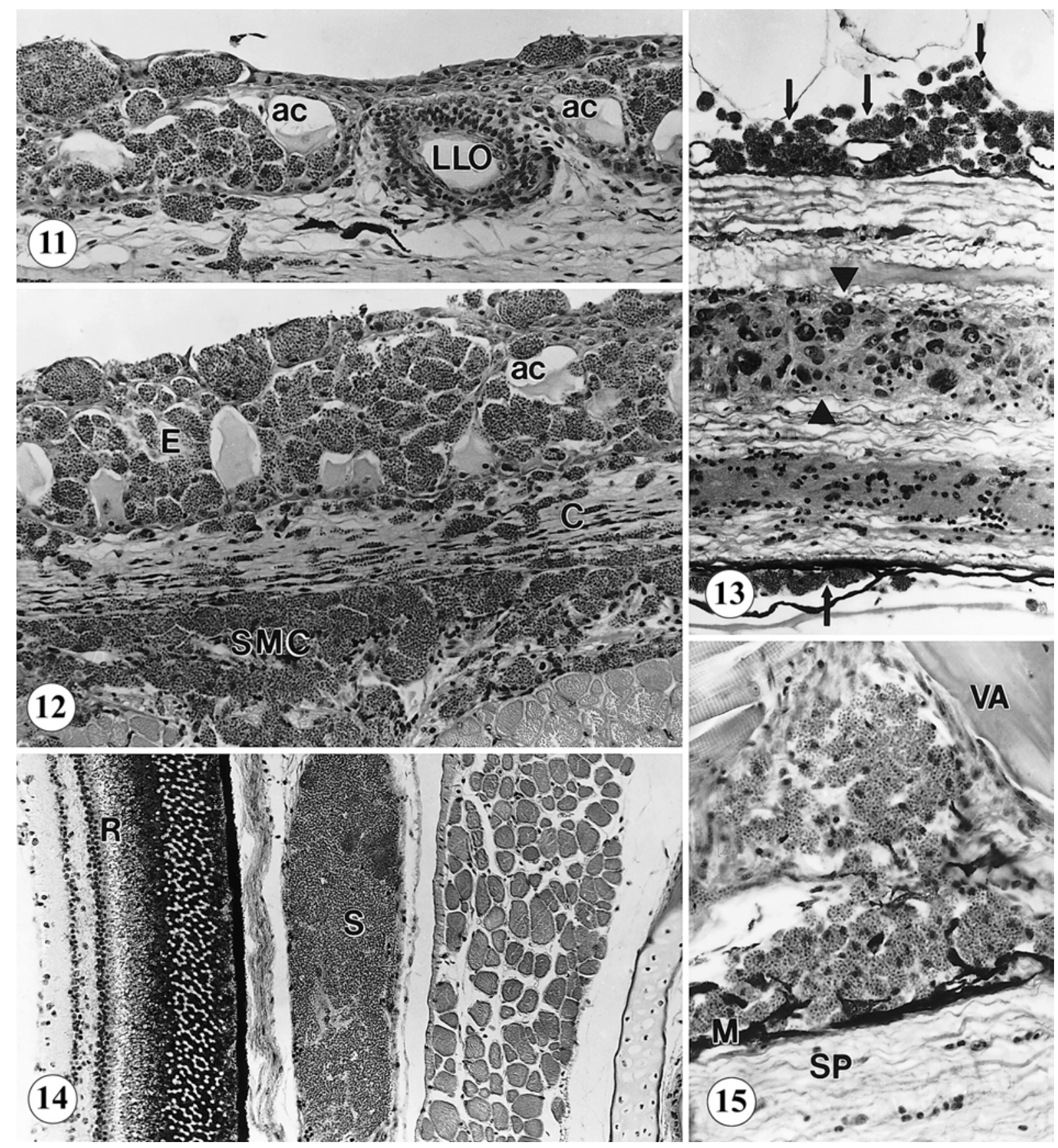

Figs. 11-15. Tissues of Pangasius sutchi infected with Kabatana arthuri, H\&E. Fig. 11. Section through epidermis with macrophages laden with spores. ac - alarm cells; LLO - lateral line organ. $\times 270$. Fig. 12. Section through the body wall tissues; spore-containing macrophages are seen in epidermis (E), corium (C) and subcutaneous muscle and connective tissue (SMC). ac alarm cells. $\times 270$. Fig. 13. Longitudinal section through the spinal cord, showing spore-containing macrophages (arrows) in meningae. Arrowhead - grey matter. $\times 230$. Fig. 14. Section through the retina $(\mathrm{R})$; the plexus of choroid blood capillaries contains a mass of spores $(S)$ and is subtended by muscle tissue. $\times 270$. Fig. 15. Macrophages replete with spores between the spinal cord and vertebrae; SP - spinal cord; M - meningae; VA - arch of a vertebra. $\times 340$.

While aggregates of spores and presporogonic stages were heavily stained with H\&E, muscle fibres which underwent necrosis revealed a homogeneous liquefied appearance and loss of staining properties. Enlarged pyknotic nuclei were observed in rows or clusters in necrotic muscle tissue, rarely also in heart muscle. 
In three fishes advanced irreversible stages of muscle destruction predominated, but only one specimen displayed signs of host inflammatory reaction. Phagocytic activity of mononuclear macrophages was the main host defence reaction. Macrophages replete with spores accumulated in lateral musculature (Fig. 6), and in the vicinity of blood vessels (Fig. 7). They were also scattered in connective and adipose tissues, in meningae (Figs. 13, 15), in the chorioidal plexus of blood capillaries (Fig. 14), in spinal ganglia (Fig. 10) and in the proximity of the peripheral nerve (Fig. 9). Exceptionally, the signs of inflammatory reaction were found in the vicinity of aggregates of macrophages with spores, appearing as infiltration by macrophages (Fig. 8). In fishes with musculature destroyed to the extent which has been just mentioned it is difficult to suppose recovery.

Lesions in epidermis were common in all specimens. The infiltration of spore-laden macrophages into the epidermis changed completely the architecture of the outer skin layer. Only the basal cell layer and some of the alarm (clavate) cells remained discernible among the macrophages (Figs. 11, 12).

\section{DISCUSSION}

In non-xenoma forming, muscle-infecting microsporidia of fish, there are several types in which the proliferating parasite affects the host tissue. In Pleistophora hyphessobryconis infections, the microsporidian occupies isolated patches in the cells always with some sarcoplasm left intact between them. The muscle fibres are seriously damaged a long time before all the available cytoplasm has been invaded. There is minimal tissue response (Dyková and Lom 1980). Rather similar is the picture of muscle tissue changes induced by infections of toad muscle by Pleistophora myotrophica (Canning et al. 1964) as well as by infections of reptiles with $P$. danilewskyi (Canning and Lom 1986). As far as can be judged by the paper dealing primarily with fine structural analysis of Trachipleistophora hominis (Hollister et al. 1996) infecting muscles of man, this species (comparable to fish Pleistophora) initially provokes lesions which are similar to those due to $P$. hyphessobryconis and which lead to complete muscle destruction.

In species such as Pleistophora ehrenbaumi or $P$. macrozoarcidis, the contents of the muscle fibres are replaced with the parasites which are closely packed within the sarcolemma with no space left between them. Fusion of several infected muscle fibres may take place. In infections with the latter species, groups of affected muscle fibres replete with mature spores may later become encased with connective tissue. Giant granulomas may arise following the fusion of several affected muscle fibres which have undergone necrotic changes (Dyková and Lom 1980).
In Heterosporis anguillarum, young developmental stages are wedged between closely adjacent muscle fibrils, only several fibrils being interrupted by the parasite. In advanced infections, the muscle is eventually destroyed by histolytic action on the muscle (T'sui et al. 1988). The granulomatous inflammatory reaction was not mentioned in this case, but was well described in infections with Heterosporis sp. in Betta splendens (Lom et al. 1993). Granulomatous myositis with macrophage infiltration was typical of the affected portions of the muscle fibre.

At variance with the preceding cases, Kabatana arthuri destroys the affected muscle fibres by producing small islands of disintegrated sarcoplasm in which the parasite stages proliferate. In the focus in which the parasite is still growing the meronts tend to be situated at the periphery while mature spores lie in the centre of the focus. This seems to be a remote analogy of the stratification in Glugea xenomas (Canning et al. 1986) and certainly is at variance with Pleistophora and Heterosporis. The parasite does not grow indefinitely. Macrophages invade the focus and ingest the spores. No granuloma formation has been observed; this might be perhaps attributable to the huge extent of the infection.

The way the parasites are localised in the muscle tissue is reminiscent of Microsporidium takedai infections in Plecoglossus altivelis and of Microsporidium seriolae infections in Seriola quinqueradiata except for the host-produced fibrous envelope in the latter species which bind the parasite masses externally (Egusa 1982). Since Lom et al. (1999) took M. seriolae to be congeneric with Kabatana arthuri, it may appear that it is the host that determines the way in which the parasite focus is structured. In Microsporidium sp. infections in Pagrus major, the destruction of muscle tissue around parasite masses similar to the two preceding ones was termed "muscle liquefaction". In photographs 2 and 3 (Egusa et al. 1988) it appears that the muscle has disintegrated to an extent similar to that observed in Kabatana arthuri and also the border line of these masses is much more broken than in the latter.

The common denominator of all fish muscle infections is the influx of macrophages that phagocytise and later digest the spores, a feature also stressed in the review by Shaw and Kent (1999). Macrophages with ingested spores may wander through the fish organism; e.g., in Pleistophora hyphessobryconis they may accumulate on the mesentery in some hosts (Canning et al. 1986) and be encased with connective tissue to form huge formations with spores still viable. What was of particular interest in Pangasius sutchi infections, however, is that these spore-laden macrophages may concen-trate in the epidermis of the skin, where they can break open, releasing into water the mostly still viable spores a long time before the host dies. This may be an efficient way of spreading the infection. 
Acknowledgements. This work was supported by grants of the Grant Agency of the Czech Republic No. 524/98/0589 and of the Grant Agency of the Academy of Sciences of the Czech Republic No. K2-022-601.

\section{REFERENCES}

CANNING E.U., ELKAN E., TRIGG P.I. 1964: Plistophora myotrophica spec. nov. causing high mortality in the common toad Bufo bufo L., with notes on the maintenance of Bufo and Xenopus in the laboratory. J. Protozool. 11: 157-166.

CANNING E.U., LOM J. (with cooperation of I. Dyková) 1986: The Microsporidia of Vertebrates. Academic Press, London, $289 \mathrm{pp}$.

DYKOVÁ I., LOM J. 1980: Tissue reaction to microsporidian infection in fish. J. Fish Dis. 3: 265-283.

EGUSA S. 1982: A microsporidian species from yellowtail juveniles, Seriola quinqueradiata, with "Beko" disease. Fish Pathol. 16: 187-192.

EGUSA S., HATAI K., FUJIMAKI Y. 1988: Notes on Microsporidium species, the etiological agent of "Beko" disease in red sea bream juveniles, Pagrus major. Fish Pathol. 23: 263-267.

HOLLISTER W.S., CANNING E.U., WEIDNER E., FIELD A.S., KENCH J., MARRIOTT D.J. 1996: Development and ultrastructure of Trachipleistophora hominis n. g., $\mathrm{n}$. sp., after in vitro isolation from an AIDS patient and inoculation into athymic mice. Parasitology 112: 143-154.
LOM J., DYKOVÁ I., SHAHAROM F. 1990: Microsporidium arthuri n. sp., parasite of Pangasius sutchi (Pangasiidae, Siluroidea) in South-East Asia. Dis. Aquat. Org. 8: 65-67.

LOM J., DYKOVÁ I., TONGUTHAI K. 1999: Kabataia gen. n., a new genus proposed for Microsporidium spp. infecting trunk muscles of fishes. Dis. Aquat. Org. 38: 39-46.

LOM J., DYKOVÁ I., TONGUTHAI K. 2000: Kabatana gen. n., new name for the microsporidian genus Kabataia Lom, Dyková et Tonguthai, 1999. Folia Parasitol. 47: 78.

LOM J., DYKOVÁ I., TONGUTHAI K., CHINABUT S. 1993: Muscle infection due to Heterosporis sp. in the Siamese fighting fish, Betta splendens Regan. J. Fish Dis. 16: 513-516.

SHAW R.W., KENT M.L. 1999: Fish Microsporidia. In: M. Wittner and L.M. Weiss (Eds.), The Microsporidia and Microsporidiosis, Am. Soc. Microbiol., Washington, D.C., pp. 418-446.

T'SUI W.-H., WANG C.-H., LO C.-F. 1988: On the Plistophora infection in eel. II. The development of Plistophora anguillarum in experimentally infected elvers, Anguilla japonica. Bull. Inst. Zool. Acad. Sin. 27: 249-258. 